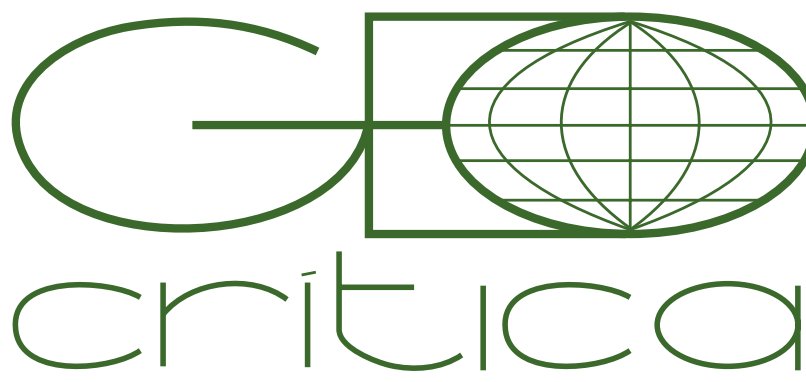

\section{Scripta Nova}

Revista Electrónica de Geografía y Ciencias Sociales Universitat de Barcelona

15 de enero de 2018

\title{
EL MEGAPROYECTO DE NUEVO VALLARTA (MÉXICO). DESTERRITORIALIZACIÓN Y AFECTACIONES AMBIENTALES
}

\author{
Mariel Massé Magaña \\ Universidad Autónoma del Estado de México \\ mari.masse@hotmail.com \\ Lilia Zizumbo Villarreal \\ Universidad Autónoma del Estado de México \\ Izv04@yahoo.com \\ Alejandro Palafox-Muñoz \\ Universidad de Quintana Roo, México \\ alejandro.palafox.munoz@gmail.com
}

\section{El megaproyecto de Nuevo Vallarta (México). Desterritorialización y afectaciones ambientales (Resumen)}

El actual modelo turístico en Nayarit, es producto de la relación Estado-corporaciones para apoyar la inversión de grupos privados, a través del despojo, lo cual ha causado diversas afectaciones ambientales. Se analizó el modelo turístico hegemónico y sus afectaciones ambientales a partir del proceso de desterritorialización para establecer el megaproyecto turístico de Nuevo Vallarta. La comprobación del supuesto anterior se fundamenta en una metodología documental y de campo bajo la categoría de desterritorialización, la aplicación de una entrevista a informantes clave para conocer las dimensiones sociales afectadas: económico, político y cultural, así como una guía de observación de impactos. Palabras clave: megaproyecto turístico, Estado, desterritorialización, acumulación, afectaciones ambientales.

\section{The Nuevo Vallarta megaproject (Mexico). Deterritorialization and environmental impacts (Abstract)}

The present touristic model in Nayarit is the outcome of the agreement between state and corporations to support private investment through dispossession, with the result of a number of environmental impacts. This study is to analyzes the hegemonic touristic model and its environmental effects as result of the deterritorialization process that established the Nuevo Vallarta touristic megaproject. To demonstrate this, it was used both documentary and field methodologies from a deterritorialization perspective; some interviews were conducted to key rural population informants who described those effects in three social areas: economic, political and cultural and also an impact observations guide. Key words: touristic megaproject, State, deterritorialization, accumulation and environmental affectations. 
La expansión turística sufrida en los litorales mexicanos parte de la idea del turismo como eje acumulación de capital ${ }^{1}$, lo cual es posible a través del sector hotelero e inmobiliario ${ }^{2}$ a gran escala para recibir grandes masas turísticas. En principio, el hallazgo de que la actividad turística es fuente generadora de ingresos a partir de la década de 1950, lleva a las naciones imperialistas a promover una política de internacionalización del turismo dentro de los países subdesarrollados ${ }^{3}$.

México, como país subdesarrollado, no ha sido la excepción gracias a las condiciones geográficas y una organización política estatal cuyos fundamentos teóricos se basan en autores como Rhina Roux, Mina Navarro, Jaime Osorio y Ralph Miliband ${ }^{4}$, entre otros, donde el Estado es el único con la capacidad de imponer intereses y proyectos privados por encima de intereses y proyectos de la sociedad en general así como las condiciones jurídicas, salariales y culturales para la valorización del valor a través de los llamados tipos de dominación: legalidad institucional, consenso y legitimidad, captura y cooptación, gestión de la gobernabilidad, disciplinamiento y normalización y la represión. Constituye una red de relaciones de poder y dominio de clases donde representa a un poder político-económico por encima de este, utiliza la violencia legítima a través de distintos aparatos institucionales (policía, milicia, etc.) para imponer las condiciones que permitan la reproducción del libre mercado pues este no puede traspasar las fronteras de los Estados nacionales sin su autorización. El capitalismo necesita de un poder político para establecerse en los territorios y este a su vez, reproduce sus valores, ambos constituyen su existencia. Es un Estado capitalista neoliberal el cual estabiliza los antagonismos de clase bajo políticas sociales; se conforma de una institucionalidad integrada por instituciones, un marco legislativo y un cuerpo administrativo. Este último, en el caso de instituciones creadas específicamente para la gestión turística, es formado en escuelas de turismo internacional para incentivar un modelo turístico hegemónico al servicio de los mercados mundiales.

En el caso de México, la actividad turística toma fuerza a partir del descubrimiento de la Bahía de Acapulco y más tarde de centros turísticos tradicionales como Puerto Vallarta, por lo que la política turística se encamina, a partir de la década de 1960, hacia un modelo de sol y playa a través de Centros Integralmente Planificados (CIP) con destinos como Cancún, Los Cabos, Ixtapa-Zihuatanejo, Loreto y Huatulco, dirigidos a una demanda internacional pero primordialmente nacional5 . De hecho, el gobierno mexicano llegó a impulsar los primeros centros turísticos tradicionales, incentivando períodos vacacionales y subsidios al gasto del turismo nacional. Sin embargo, a partir de la entrada del modelo neoliberal, se fortalece la política de internacionalización del turismo dentro del país con la planificación y replanificación de megaproyectos turísticos tipo enclave, cada vez más especializados, elitistas y ex-

1 Cordero 2003; Palafox 2011, 2013.

2 Palafox 2010.

3 Lanfant 1980.

4 Roux 2005; Navarro 2015; Osorio 2012, 2014; Miliband 1969.

5 Benseny 2007. 
clusivistas para una creciente demanda de altos ingresos sobre todo internacional. Hasta hoy, se han impulsado regiones como Nayarit, Cozumel, Sinaloa y una serie de marinas en la región de Baja California.

Los CIP a cargo del Fondo Nacional de Fomento al Turismo (FONATUR) se han pensado como polos de desarrollo en áreas de costa donde no existe ningún otro tipo de actividad productiva. Para su construcción se requiere de vías regionales, marinas y aeropuertos; una infraestructura de gran capacidad y lujo (hoteles, campos de golf, centros comerciales y servicios de entretenimiento). La lógica vista en los enclaves se basa en dos modalidades distintas: por un lado, excluyen totalmente a las poblaciones locales y por otro, llegan a integrar un espacio para la mano de obra tanto operativa como de construcción, ya sea proveniente de la población local o de un efecto migratorio ${ }^{6}$. Nuevo Vallarta se ha desarrollado a partir de poblaciones y servicios urbanos existentes tanto de los poblados aledaños como de Puerto Vallarta, Jalisco. Cabe mencionar que FONATUR es la principal institución creada para la atracción de inversionistas privados tanto nacionales como extranjeros, la gestión del territorio para su privatización, financiar empresas turísticas y en muchos casos proveer infraestructura de tipo carretera y aérea, urbanización o de servicios básicos para facilitar la llegada de grandes inversiones.

Aquí es importante mencionar que para la gestión del territorio por parte del Estado, este mismo ha modificado su uso y propiedad en demanda de nuevas formas productivas, impulsadas a partir de las políticas neoliberales aunado a una minimización de los estándares ecológicos. En concreto, se reforma al artículo 27 constitucional donde se abre toda posibilidad de apropiación de tierras comunales y ejidales a la forma tanto pública como individual. En otras palabras, se rompe el ejido como institución intocable donde la propiedad de la tierra se abre a la oferta y demanda en manos de particulares ${ }^{7}$. En este sentido, existe un pacto Estado-corporaciones ${ }^{8}$ para desterritorializar, es decir, para privatizar el territorio, separar a los campesinos de sus tierras y despojarles de sus capacidades productivas para generar mercancías.

El fundamento teórico para la desterritorialización parte del geógrafo brasileño Rogerio Haesbaert, quien se apoya en aportaciones previas de Deleuze y Guattari. Por otro lado, si bien la propuesta de David Harvey de acumulación por desposesión podría tener una íntima relación con el planteamiento de una acumulación de capital a través de la desterritorialización (entendida como despojo, desposesión, separación de productores y sus medios de producción, la esencia del nuevo modelo neocapitalista), aquí se pretende construir un modelo teórico-metodológico propio donde se elige la categoría de desterritorialización bajo las aportaciones de Rogerio Haesbaert ${ }^{9}$, para caracterizar la forma cómo se dio la desterritorialización en el caso de Nuevo Vallarta.

\footnotetext{
6 Dávila 2015.

7 Olivera 2005; Monterroso y Zizumbo 2009.

8 Portilla 2005.

9 Haesbaert 2011.
} 
La desterritorialización representa el momento trascendental entre una etapa previa de penetración de reformas estructurales, en este caso una política turística junto a otras más, y el proceso de acumulación, donde finalmente operan los megaproyectos turísticos en las costas mexicanas, con una serie de afectaciones ambientales. Estos tres procesos son en sí mismos la construcción del modelo teórico-metodológico mencionado con base en una propuesta anterior ${ }^{10}$ para el análisis de la constitución de un modelo turístico hegemónico en México, donde se identifica la interrelación de tres elementos: el Estado, el capital turístico y el territorio.

El territorio, como categoría de análisis, no sólo se refiere al espacio despojado en su forma física sino aquel donde se ejercen relaciones sociales diversas entre individuos-sociedad-naturaleza dentro y fuera de este ${ }^{11}$. Principalmente se encuentran dos tipos de relaciones sociales respecto al territorio: a) de poder en busca de privatizar el espacio físico para la acumulación de capital, fracturando otro tipo de relaciones sociales ejidales o comunitarias preexistentes o inclusive esto puede provocarse antes para poder penetrar en el territorio y b) de aprovechamiento a una escala de subsistencia para la reproducción de la vida de pequeñas poblaciones. En este sentido, las dimensiones territoriales se identifican en lo político-económico y lo cultural-simbólico.

Bajo la propuesta teórico-metodológica expuesta, el presente artículo está constituido por dos apartados principales: el primero analiza el proceso de desterritorialización a partir de la política de internacionalización del turismo; en el segundo se trata el actual momento de acumulación, donde es operado el megaproyecto turístico de Nuevo Vallarta, el cual ha ocasionado una serie de impactos ambientales negativos en el territorio, expresados en voz de los propios entrevistados. Finalmente, se expone el apartado de conclusiones tras el análisis en profundidad del análisis teórico-metodológico argumentado en este primer apartado introductorio y el trabajo de campo realizado con la aplicación de una entrevista semiestructurada a informantes parte de los ejidatarios afectados tras la expropiación de sus tierras, es decir, tras el proceso de desterritorialización.

\section{La mediación estatal y el proceso de desterritorialización}

El impulso al proyecto de desarrollo de Bahía de Banderas (Mapa 1) dentro de la política de internacionalización del turismo y la modificación estructural de la región Costa Sur de Nayarit, parte de aspectos particulares. El proceso de desterritorialización se dio bajo la forma de expropiación donde intervino el Estado para dar legalidad institucional y con ello, el consentimiento de la población afectada.

El 10 de noviembre de 1970, se expide el Decreto único correspondiente de expropiación bajo la presidencia del Lic. Gustavo Díaz Ordaz, a favor del Fideicomiso Traslativo de Dominio Bahía de Banderas para desarrollo turístico, publicado el 18

10 Vilchis et al 2016.

11 Haesbaert 2011; Lefebvre 1976. 


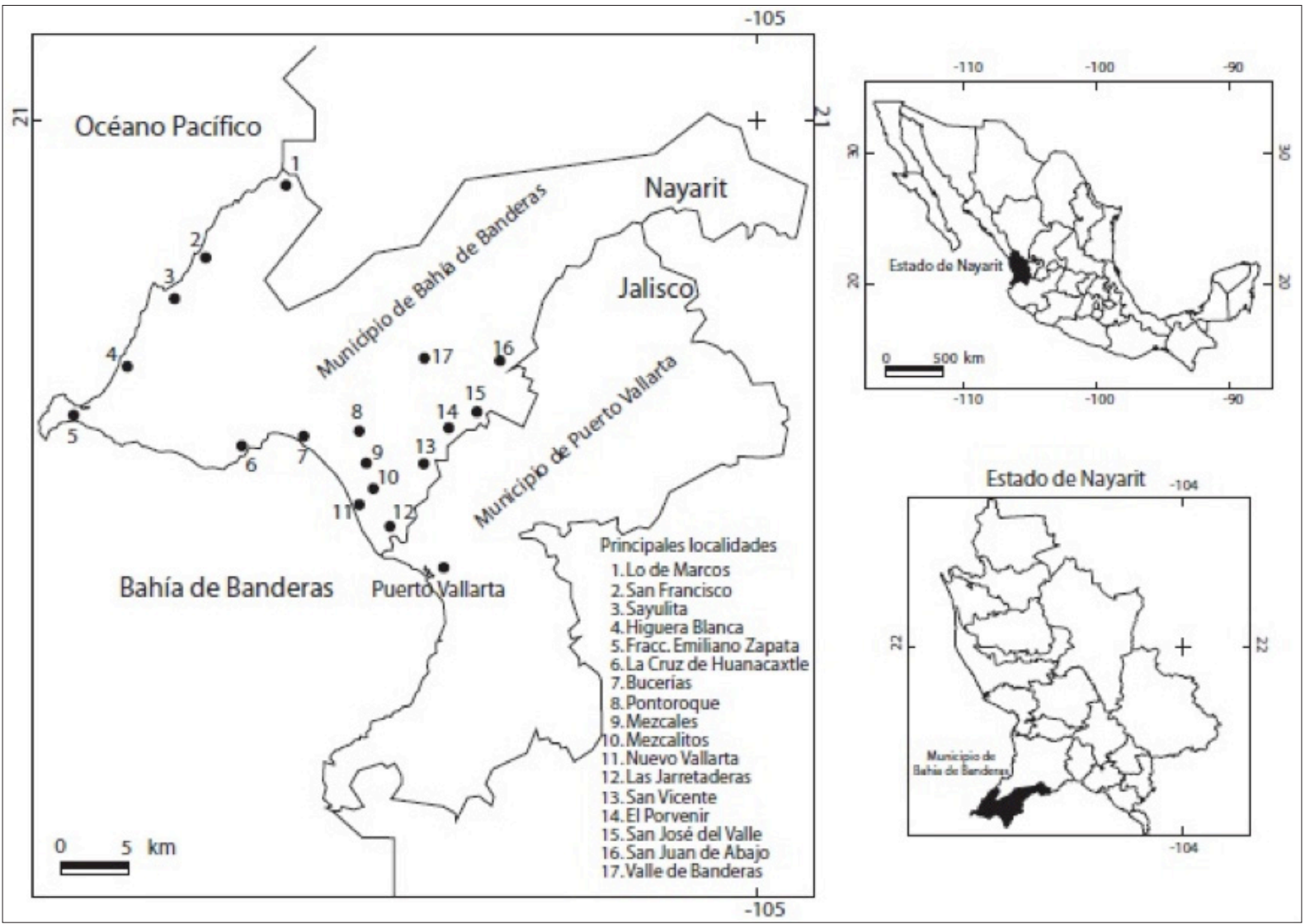

Mapa 1. Localización del área de estudio Fuente: Márquez y Sánchez 2007.

del mismo mes en el Diario Oficial de la Federación ${ }^{12}$. El decreto, ausente de consulta pública, declaró: “... de utilidad pública el desarrollo habitacional y turístico en los terrenos que circundan la Bahía de Banderas, ubicados en las costas de Nayarit y Jalisco, así como el mejoramiento de los centros de población... y sus fuentes propias de vida" y en su Artículo Segundo: “... se decreta la expropiación a favor del Gobierno Federal, representado por la Secretaría del Patrimonio Nacional, de las siguientes superficies ejidales del Municipio de Compostela, Estado de Nayarit: La Jarretadera 382 hectáreas; Bucerías 440 hectáreas; Cruz de Huanacaxtle 375 hectáreas; Higuera Blanca 1083 hectáreas; El Capomo 329 hectáreas, que en total hacen una superficie de 4136 hectáreas; y en Municipio de Puerto Vallarta, Estado de Jalisco 1026 hectáreas del ejido de Puerto Vallarta". La infraestructura ya existente -carreteras, aeropuerto, servicios básicos e infraestructura urbana- aunado a un ecosistema privilegiado y de alto valor paisajístico y la realización de operaciones legales de compra-venta de terrenos ejidales, fueron algunos aspectos para consumar la expropiación, pues ello detonaría el desarrollo de la región y el mejoramiento del nivel de vida de los pobladores bajo el uso racional de los recursos.

El 18 de enero de 1973 fue publicado un nuevo decreto mediante el cual, el presidente Luis Echeverría Álvarez, reforma el artículo quinto del Decreto de 1970, para separar las 1026 hectáreas expropiadas al ejido de Puerto Vallarta y crear por sepa-

12 Diario Oficial de la Federación 1970. 
rado los fideicomisos de Puerto Vallarta y Bahía de Banderas: “... la operatividad del Fideicomiso en cuestión en cuanto a las áreas expropiadas a los respectivos ejidos de los Estados de Jalisco y Nayarit, hace ver la conveniencia de que se manejen autónomamente, esto es, por medio de sendos fideicomisos traslativos de dominio, lo que redundará en la pronta realización de sus fines, con la obvia conveniencia de que los campesinos beneficiarios de dichos fideicomisos puedan recibir cuanto antes su indemnización y participen en las utilidades y ganancias que genere el complejo habitacional y turístico que habrá de desarrollarse en los terrenos desincorporados del régimen ejidal, manejados a través de dos distintos fideicomisos, motivaciones suficientes para introducir las reformas adecuadas al artículo quinto del decreto en cita..."13.

El Fideicomiso Bahía de Banderas (FIBBA) había sido creado por disposición federal para servir como gestor intermediario entre la política federal y del estado en las organizaciones de la ruralidad mexicana, conformada por ejidos y comunidades localizadas en los territorios expropiados por la federación con el fin de impulsar la venta y promoción de terrenos para el desarrollo inmobiliario turístico del litoral. Sus finalidades se encaminaron principalmente a rodear Bahía de Banderas con un desarrollo habitacional.

A partir de esto, el fideicomiso trazó dos tipos de programas: sociales y turísticos. Los programas sociales se implementarían en los poblados comprendidos dentro de la zona de influencia del FIBBA. Bajo estos programas se contempló el desarrollo de infraestructura urbana, desarrollo educativo, desarrollo de la comunidad, servicios asistenciales, unidades deportivas, organización de pescadores y otros más. Esto les permitiría realizar actividades diferentes a la agricultura a cambio del despojo de sus tierras por parte del gobierno. No fue un proceso simple, hubo conflictos pues las tierras vistas con potencial turístico, antes de ser pagadas a los afectados, fueron negociadas a cambio de terrenos en Quintana Roo o Chiapas. La gente se opuso ante esto y derivado de ello, se llegó al acuerdo de retribuir monetariamente a los ejidatarios por sus parcelas. Fue así como se les pagó 3 centavos el metro, actualmente se vende en 5 mil $^{14}$. El 3 de julio de 1971, en la Peñita de Jaltemba, el presidente Lic. Luis Echeverría Álvarez, puso en marcha el desarrollo turístico de la zona, con la entrega de 7 millones de pesos al Fondo Común Ejidal ${ }^{15}$.

Otro de los objetivos fue que el Fideicomitente (Gobierno Federal), enviaría al Fondo Nacional de Fomento Ejidal (FONAFE), las utilidades y productos de las ventas para beneficio de los ejidatarios. Es decir, la indemnización anunciada en la Peñita convertía en socios a los ejidatarios de las empresas derivadas del complejo turístico: clubes de yates, hoteles, conjuntos de bungalows, etc. En octubre de ese año, apenas unos meses después, el Gobernador del Estado de Nayarit, Lic. Roberto Gómez Reyes, anunciaba los avances del complejo turístico más grande de

13 Suárez 1973; Diario Oficial de la Federación 1970.

14 Alejandro Dávalos. Comunicación personal.

15 El Informador 1971a. 
América Latina, "Zona Turística de Costa Alegre"16. Se iniciaron obras en todos los ejidos poniendo especial interés en el desarrollo de los Fraccionamientos Playas de Huanacaxtle, Flamingos Vallarta, Fraccionamiento Rincón de Guayabitos, Club de Golf y Tenis Flamingos, Nuevo Vallarta, Fraccionamiento Emiliano Zapata y Playas Populares.

El 10 de abril de 1974, ejidatarios e inversionistas firmaron un acuerdo para invertir 300 millones de pesos en el fraccionamiento Náutico Nuevo Vallarta. En esos días, el Fideicomiso firmó con el Ing. Percy Cliford la construcción de un campo de Golf de 18 hoyos en "El Quelele" con el compromiso de terminarlo en un año ${ }^{17}$. El 5 de julio del mismo año, se publicó un segundo decreto para expropiar otras 100 hectáreas al ejido de Bucerías para integrarlas al patrimonio del Fideicomiso a fin de poder construir el campo de golf.

El modelo de desarrollo turístico previsto para las áreas expropiadas, viene a ser legalizada por el decreto presidencial de Luis Echeverría Álvarez (1970-1976) de 1971 con la formación de fideicomisos en las fronteras y costas para poder desterritorializar a los ejidatarios, engañándolos de ser socios de las empresas turísticas fideicomisadas, pues no recibían información veraz ni transparente ni podían decidir sobre el más mínimo asunto ${ }^{18}$. Se prometió una participación campesina no solo a través de negocios ganaderos sino mediante la realización de negocios industriales, comerciales y turísticos. Esta nueva modalidad para lograr el desarrollo regional, se perfiló con base a un diagnóstico de la realidad económico-social del área expropiada, lo cual condujo a la aplicación del plan maestro. De esta manera, Echeverría, se convierte en el primer promotor turístico de Bahía de Banderas a nivel internacional, cuyo proyecto requería de las acciones llevadas a cabo durante la presidencia de su antecesor Gustavo Díaz Ordaz (1964-1970).

Al término de la década de los años 80 , se divide la parte sur del municipio de Compostela para crear Bahía de Banderas como el municipio número 20. El desarrollo turístico propuesto en el área expropiada fue impulsado bajo la modalidad de los "polos de desarrollo" o Centro Integralmente Planeado para el impulso de la actividad turística dentro del Plan Nacional de Desarrollo. Se pensaba que, al poner a funcionar un polo turístico, este irradiaría una mayor actividad económica y por consiguiente el desarrollo integral de la región. Los poblados mayormente impulsados fueron Sayulita, La Cruz de Huanacaxtle, Bucerías, Punta Mita y Nuevo Vallarta (estos dos últimos con un desarrollo tipo enclave) hasta los límites del Río Ameca y el ejido de Jarretadera. Los primeros tres ligados al contexto local, los dos últimos exclusivos de un desarrollo tipo enclave.

El mejoramiento de la población y de sus condiciones de vida, como lo estipulaba el decreto, significó la urbanización de los poblados, apoyo a proyectos productivos donde muchos ejidatarios se verían beneficiados con aportaciones federales para

16 El Informador 197lb.

17 El Informador de Guadalajara. 3 abril 1974.

18 Gómez 1974. 
la ganadería, sobre todo la clase política local que incluso ocupó puestos directivos en los diferentes programas. Estos aspectos, son reconocidos como las principales acciones de mediación por parte del Estado, lo cual deja ver diversos tipos de dominación sobre la población: legalidad institucional, gestión de la gobernabilidad, consenso y legitimación, captura y cooptación, normalización y disciplinamiento ${ }^{19}$ para permitir el desarrollo de un modelo turístico hegemónico y minimizar el impacto de la expropiación de las tierras sobre las cuales tendrían un beneficio, del cual más tarde el gobierno se desentendería.

Particularmente, el programa de regeneración de los pueblos fue materializado con la introducción de obras de infraestructura urbana básica: construcción de caminos de acceso, alineación de calles, electrificación, agua, drenaje, la instalación de centros de desarrollo y de servicios asistenciales, una primaria en cada poblado, una secundaria, un hospital, fábricas en San Pancho como la Compañía Nacional de Subsistencias Populares (CONASUPO), una preparatoria ubicada más tarde en la Cruz de Huanacaxtle, así como la transformación del tipo de vivienda. Las casas de palapa a base de palos y palmas, fueron derribadas para construir viviendas más grandes de material, ladrillo, loza y cemento, con 3 recámaras, sala, cocina y baño en su interior, alrededor de unos $500 \mathrm{~m}^{2}$ para lo urbanizado y $1500 \mathrm{~m}^{2}$ más para las actividades agrícolas. Incluso, se les regaló 1 año entero del servicio de luz eléctrica. En este sentido, el nivel de vida de la población en comparación con algunos extranjeros ya establecidos, no era tan desigual. Este proyecto significaba un nivel de vida aceptable, más avanzado y moderno, comparado con las chozas donde los campesinos vivían.

El Fideicomiso, marcó el comienzo de expansión turística y penetración de capitales extranjeros a la región para la dominación de los espacios de producción tradicionales y el control sobre la compra-venta de tierras ejidales entre las décadas 70-80. Bajo este contexto, se planearía un enclave exclusivo para la recepción de una demanda con alto poder adquisitivo nacional e internacional para estadías tanto temporales como residenciales. Dos partes fundamentales conformarían a este organismo, el Estado y una unión ejidal, la cual, de acuerdo con el decreto, debía ser beneficiada con la compra-venta de tierras y la obtención de utilidades a partir de la operación de servicios turísticos en las tierras expropiadas. De acuerdo con informantes clave, el fideicomiso apoyó por un tiempo a la contribución de ingresos, pero al liquidarles, se firmó un acuerdo donde se estableció no habría ningún tipo de responsabilidad u obligación por parte de este. Esto demuestra un deslinde de los objetivos de su creación y responsabilidad competente, pues muchas de las tierras no fueron pagadas a los ejidatarios afectados cuando su finalidad había sido acordada para proteger su integridad y tener acceso a las utilidades generadas por estas, pero no fue así. Entre las contradicciones y faltas legales, se dio también la venta de tierras sin consentimiento de los ejidatarios y otras más no remuneradas: "No se me ha pagado por las tierras expropiadas"-Guadalupe de Jesús-. Las prioridades del

19 Navarro 2015. 
fideicomiso, iban encaminadas hacia intereses de otro tipo, como el campo de golf los Flamingos, a donde se iba todo el dinero.

Desde entonces se aceleró el proceso de transformación en la Zona de Costa que había iniciado con la construcción de la Carretera Federal 200. En la Cruz de Huanacaxtle, se construyó un muelle para los barcos pesqueros, rompeolas en Peñita de Jaltemba y canales navegables en Nuevo Vallarta para impulsar los programas pesqueros y turístico-náuticos.

Sin embargo, la desterritorialización a través de la expropiación, trajo un efecto directo a los programas agrícolas, ganaderos, pesqueros, industriales, educativos y de vivienda popular de 60 mil hectáreas, provocando la inconformidad de muchos ejidatarios. En la búsqueda de encaminar todos los esfuerzos hacia la actividad turística, se dio una reconfiguración de los aspectos políticos, económicos y culturales de la región. También una serie de conflictos internos entre estos, debido a los despojos, ventas y construcciones turísticas, ya que por más de 10 años trataron de regularizar sus tierras, sin el éxito esperado ${ }^{20}$. Aunado a ello se dio un incremento del valor de las tierras, lo cual provocó una demanda de visitantes más selectos y la valorización de los bienes naturales. En este sentido, fue posible justificar la apropiación del territorio, donde intervino la reconfiguración del uso de suelo de actividades primarias a uso urbano turístico-habitacional.

Entre 1975 y 1984, se dio un importante incremento de la oferta de alojamiento en grandes y modernas instalaciones hoteleras, unidades de tiempo completo y compartido, nuevos equipamientos como la marina y campos de golf basados en un modelo de alta densidad. Un aspecto importante se dio en este tiempo, pues en junio de 1977, el nuevo director del Fideicomiso, Federico Martínez Manautou, acusó de fraude por 500 millones de pesos a su anterior director, Alfredo Ríos Camare$\mathrm{na}^{21}$. Ante dicho fracaso económico, la inversión federal en obras del Fideicomiso se detuvo. En ese mismo año, la Compañía Constructora Siete, encargada de "la rehabilitación de los poblados" fue embargada y rematadas sus unidades para cubrir pagos de trabajadores y proveedores. Para diciembre, se anunció la desaparición del FONAFE con una pérdida de 1500 millones de pesos y 27 empresas ejidales, entre ellas el Hotel Bucerías, controladas por la Secretaría de Agricultura y Recursos Hidráulicos. Las pérdidas anunciadas, formaban parte de las utilidades y producto de las ventas para beneficio de los ejidatarios ${ }^{22}$.

El gobierno del Lic. José López Portillo retomó el proyecto del Fideicomiso, desprovisto de su mística social que priorizaba el desarrollo turístico. El 13 de mayo 1978, el mandatario inauguró la Plaza Pública de Jarretadera, supervisó el avance de los canales navegables de Nuevo Vallarta e inauguró el Campo de Golf Flamingos ${ }^{23}$. El 6 de diciembre de 1980, inauguró el Club de Playa Nuevo Vallarta, la escollera del pueblito náutico "Nuevo Vallarta", una red de agua potable, la planta de tratamiento

20 Martínez 2009.

21 El Informador 1977.

22 Ibíd.

23 El Informador 1978. 
de aguas negras, la sub-estación eléctrica "Vallarta II" en Nuevo Vallarta para dar servicio a todos los pueblos de la Zona Costa y el fraccionamiento turístico Playas de Huanacaxtle ${ }^{24}$.

El turismo se perfilaba ya como la actividad económica principal. En este proceso de internacionalización de Bahía de Banderas se pueden visualizar dos períodos: de 1987 a 1993 con mayor interés en la región y el segundo a partir de 1993, sobre la base de optimizar el uso de recursos en los municipios, a través de la descentralización de organismos instituidos para el fomento y desarrollo turísticos, tomando en cuenta las zonas donde se verían reflejados estos dos momentos de transformación. Por un lado, el 24 de febrero de 1989, las secretarías Programación y Presupuesto, Reforma Agraria, Hacienda y Crédito Público, Contraloría General de la Federación; el Gobierno del Estado de Nayarit, el Banco Nacional de Obras y Servicios Públicos, el Fideicomiso y la empresa Nuevo Vallarta S.A., suscribieron un acuerdo que dejó sin efecto el Contrato del Fideicomiso del 29 de enero de 1971 y todas sus modificadores a este ${ }^{25}$ y por otro lado, la SECTUR fue extendida hacia representaciones estatales. Ambas acciones para una pronta incorporación al proceso de modernización.

A finales del sexenio de Miguel de la Madrid -6 de mayo de 1988- el titular de la Reforma Agraria, anunciaba en Tepic el Proyecto de Transferencia del Fideicomiso en manos del gobierno federal. Y el 3 de junio de 1989, Carlos Salinas de Gortari autorizó en la misma ciudad el traspaso de éste a manos del gobierno estatal de Nayarit. Esta transferencia y la creación del nuevo Municipio, facilitó la adquisición de terrenos a hizo más eficiente la administración pública a los inversionistas. Con base al nuevo convenio que dejaría sin efecto al Fideicomiso, da inicio la sesión de derechos "a terceros" y se desarrolla Nuevo Vallarta, Pueblito Paraíso-Paradise Village.

Dentro de este marco permisible, en junio de 1990, fue celebrado el Convenio de Reubicación entre pobladores de Corral de Risco -asentados desde 1942- con 479 habitantes en 101 viviendas, la Secretaría de Desarrollo Social, el Fideicomiso y dos empresas inmobiliarias para la creación del proyecto Costa Banderas, dueños entonces de los terrenos de Punta Mita. Este desarrollo contaría con una longitud de 21 kilómetros sobre 1056 hectáreas. Dentro del perímetro, se construirían en un periodo de 10 años: cuatro o cinco campos de golf, marina para lanchas deportivas y de pesca, un aeropuerto privado y hoteles de gran turismo en manos de las firmas trasnacionales Four Seasons, Princes, Rockefeller Resort, Ritz Carlton y Quinta Real. Así mismo, la pequeña población de El Papayal fue reubicada al ejido de Jarretadera para iniciar la expansión del enclave de Nuevo Vallarta. En 1993, Mayan Palace, hoy Grupo Vidanta de capital nacional, adquirió alrededor de 60 hectáreas en la misma área y en 1997 arrancó sus operaciones con 115 habitaciones ${ }^{26}$.

La extensión territorial no fue adquirida a través de una sola operación de compraventa, sino en todo un proceso que duró dos décadas. El primer predio fue en

24 El Informador 1980.

25 Gobierno del Estado de Nayarit 2014.

26 Benavides 2015. 
1993, de acuerdo con testimonios de residentes tanto de Jarretadera como de Nuevo Vallarta; estas tierras fueron cedidas o vendidas a Vidanta en los términos establecidos por éste. Fueron sus abogados quienes redactaron el contrato de venta o donación y no por alguna empresa gubernamental vendedora. Por ello existe la fuerte creencia de que el pago por los terrenos fue mínimo al precio real.

Un año después, el grupo DINE S.A. de C.V., declaró ser encargado de construir un complejo turístico en Punta Mita donde se estableció Four Seasons. Este hotel de gran clase empezó a construirse en 1994 sobre una superficie de 70 hectáreas, pero modificada unos años después. De esta manera, comienza el desarrollo de Jarretadera-Nuevo Vallarta y Punta Mita-Litibú, áreas prioritarias para la atracción de una clientela exclusiva con altos ingresos económicos ${ }^{27}$. Para consolidar la inversión y promover el desarrollo de este tipo de turismo, el primer gobierno municipal trabajó conjuntamente con el Fideicomiso declarando los territorios expropiados como área de uso turístico.

Sin embargo, parte de la población entrevistada da cuenta de disputas, irregularidades jurídicas y legales, así como abuso por parte de las autoridades del Estado, cuya intervención, ha sido considerada en detrimento de la población. Por ejemplo, las dos pequeñas poblaciones asentadas en el espacio que hoy ocupa Nuevo Vallarta, tuvieron que trasladarse al ejido de Jarretadera, éste afectado también por la cesión de territorio al megaproyecto y debido a que ambos colindan, el poblado se ha visto cada vez más reducido en su extensión debido al convencimiento de algunos ejidatarios por vender al grupo Vidanta. Se habla de un proceso de convencimiento cuya duración fue de aproximadamente 3 años, donde se vivió un efecto migratorio de otras partes colindantes a la región a partir de los beneficios prometidos. Esto ocasionó la fragmentación de la población en dos grupos: por un lado, los opositores de edad avanzada y por otro, los convencidos, en su mayoría jóvenes y personas recién llegadas. Los ejidos ubicados sobre la costa, así como los pueblos de la región montañosa, sufrieron transformaciones como parte de la reestructuración urbana de la región tras el impulso a la actividad turística. Pero estos últimos sufrieron además un crecimiento habitacional anexo tras el efecto migratorio provocado por la expansión turística. De manera general, el despojo surge a partir del cambio de uso de suelo, provocando desplazamientos, el acceso denegado de las playas que abarca el desarrollo de Nuevo Vallarta, conflictos en la cesión de tierras a grupos privados dentro de este, así como el crecimiento poblacional en los alrededores de la región.

Las acciones políticas se encaminaron a la promoción de nuevas inversiones a través del aprovechamiento de recursos y buscar la consolidación de aquellos enclaves ya establecidos: Nuevo Vallarta y el corredor Cruz de Huanacaxtle-Punta Mita. El crecimiento inmobiliario fue descomunal entre 1992 y 1997, cuyo incremento anual fue del 12.8\%, es decir, 252.2 cuartos al año o 2 cuartos cada tercer día. De 1997 a 2000 el número de unidades rentables creció $60 \%$, alcanzando 5390 unidades en 94 establecimientos, entre hoteles 5 estrellas y condominios. Nuevo Vallarta parti-

27 Ángel 2005. 
cularmente, albergaría la mayor cantidad de oferta hotelera de primer mundo de la región y con ello la demanda turística del más alto poder adquisitivo. Fue identificado como la estrategia más viable para alcanzar un desarrollo regional y dinamizar con ello la economía del Estado, con el cual se apostaría por la internacionalización de la región como destino de clase mundial. Se estima actualmente la existencia de más de 808 unidades de condominios, principalmente en Nuevo Vallarta, además de segundas residencias no registradas.

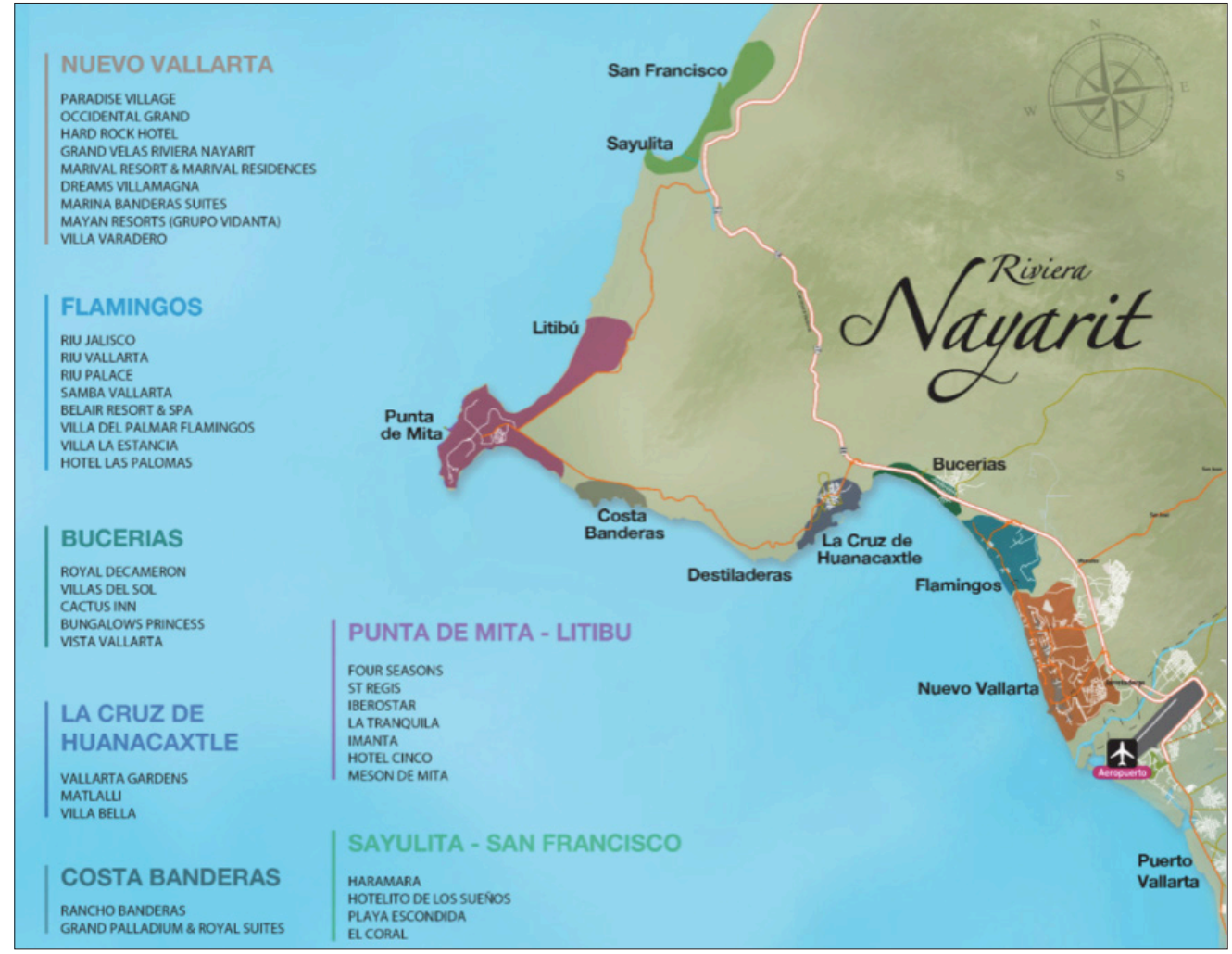

Mapa 2. Riviera Nayarit

Fuente: http://www.rivieranayarit.com/etc/nayarit/cr_files/mexico/SalesMaterial/MAPA_Hoteles.jpg

Desde 2005, en competencia del desarrollo de Puerto Vallarta, se impulsa la promoción de "Riviera Nayarit" (Mapa 2) como marca para posicionar de manera sólida a la región de Bahía de Banderas ${ }^{28}$, la cual nace con el Proyecto de la Escalera Náutica de la Región del Mar de Cortés, un proyecto de carácter regional para brindar una oferta integral de infraestructura y servicios de apoyo náutico, carretero y aéreo, mediante la integración por etapas de 20 puertos de abrigo y paradores náuticos, el desarrollo de un puente terrestre para el traslado de embarcaciones del Océano Pacífico al Mar de Cortés, el mejoramiento de cinco rutas de acceso desde la zona fronteriza para embarcaciones remolcables, la integración de una red aeroportuaria de apoyo y de un sistema de abastecimiento de combustibles, así como acciones para facilitar la internación de turistas y equipos náuticos ${ }^{29}$. 
Con los convenios firmados entre el Fondo Nacional de Fomento al Turismo (FONATUR), los municipios y el gobierno estatal; nacen las acciones tendientes del proyecto Riviera Nayarit, para el cual se planteó la construcción de 30 nuevos hoteles, cuatro campos de golf, dos marinas náuticas y un aeropuerto a lo largo de 175 kilómetros de playa. Los principales puntos de interés serían las playas de Lo de Marcos, San Francisco o San Pancho, Sayulita (Pueblo Mágico desde 2015) ${ }^{30}$, Nuevo Vallarta, Cruz de Huanacaxtle, Bucerías y Punta Mita-Litibú. Nuevamente, bajo el argumento de aprovechar los bienes naturales, la promesa de generar empleos y como alternativa de desarrollo regional.

No obstante, a pesar de las positivas promesas, ha sido posible detectar el surgimiento de problemas relacionados a la compra-venta de grandes zonas de tierras mayormente ejidales a precios irrisorios, el despojo de tierras a aquellos que se negaron a vender y al mismo tiempo una venta ilegal de terrenos comunales, la privatización de estos por instancias federales e inversionistas privados, la presencia de abuso de poder y autoridad por orden estatal y municipal, aunado al deterioro del ambiente natural, entre otras cuestiones.

La desterritorialización no sólo se ha dado por la expropiación sino a través de distintos casos de despojo dentro de la región, evidenciados gracias a los diarios locales. Se tiene el caso de la población de Lima Abajo, a un kilómetro de la Playa el Naranjo con una extensión de $15 \mathrm{~km}$, cuya dinámica era una economía local con la venta de alimentos, palapas como tipo restaurantes rústicos, lo cual duró aproximadamente 15 años. En 2008, el FONATUR determinó esta zona como propicia para el desarrollo de un proyecto. Se indemnizó a los ejidatarios a pesar de su renuencia. Otro, fue el caso de la población de Monteón, la cual incluso se organizó para defender la propiedad ejidal debido a la venta ilegal de aproximadamente 25 hectáreas de bosque tropical, con lagunas naturales, esteros y manglares, aspectos puntuales para el interés de capitalistas privados.

Otro más, fue el desalojo de la población en Punta Mita, cuya historia de despojo, referenciada por algunos entrevistados, ha sido a través de la violencia física y la destrucción de los asentamientos de la población pesquera Corral de Risco, para construir los hoteles San Reyes y Four Seasons, existiendo evidencia fotográfica del derrumbe de las casas de la población. Esta experiencia presentó una tensión importante, cuando la policía municipal cerró el acceso a la playa, originando una confrontación entre esta y los ejidatarios. Llegó a haber detención de líderes representantes del poblado. Entre otros actores sociales, también participaron personajes políticos de izquierda, quienes denunciaron al gobierno estatal en turno por permitir la compra de tierras para desarrollar complejos de lujo. Mucho de esto por una ausencia importante de beneficios para la población local, la existencia de irregularidades ambientales y las formas violentas de desterritorialización supuestamente con el fin de proteger los espacios adquiridos por el Fideicomiso ${ }^{31}$.

30 SECTUR 2016.

31 Real, Olivarría y Madera 2010; Emilia Reyes. Comunicación personal. 


\section{Nuevo Vallarta a partir de las dinámicas capitalistas y sus afectacio- nes ambientales, proceso de acumulación}

El territorio expropiado al ejido de Jarretadera, era un territorio preciado por su colindancia con Puerto Vallarta que en los años 70's era un destino turístico inmerso en un firme proceso de consolidación. Incluir el nombre de Vallarta en la nueva localidad sería con el interés de capitalizarla cercanía y el reconocimiento internacional del puerto.

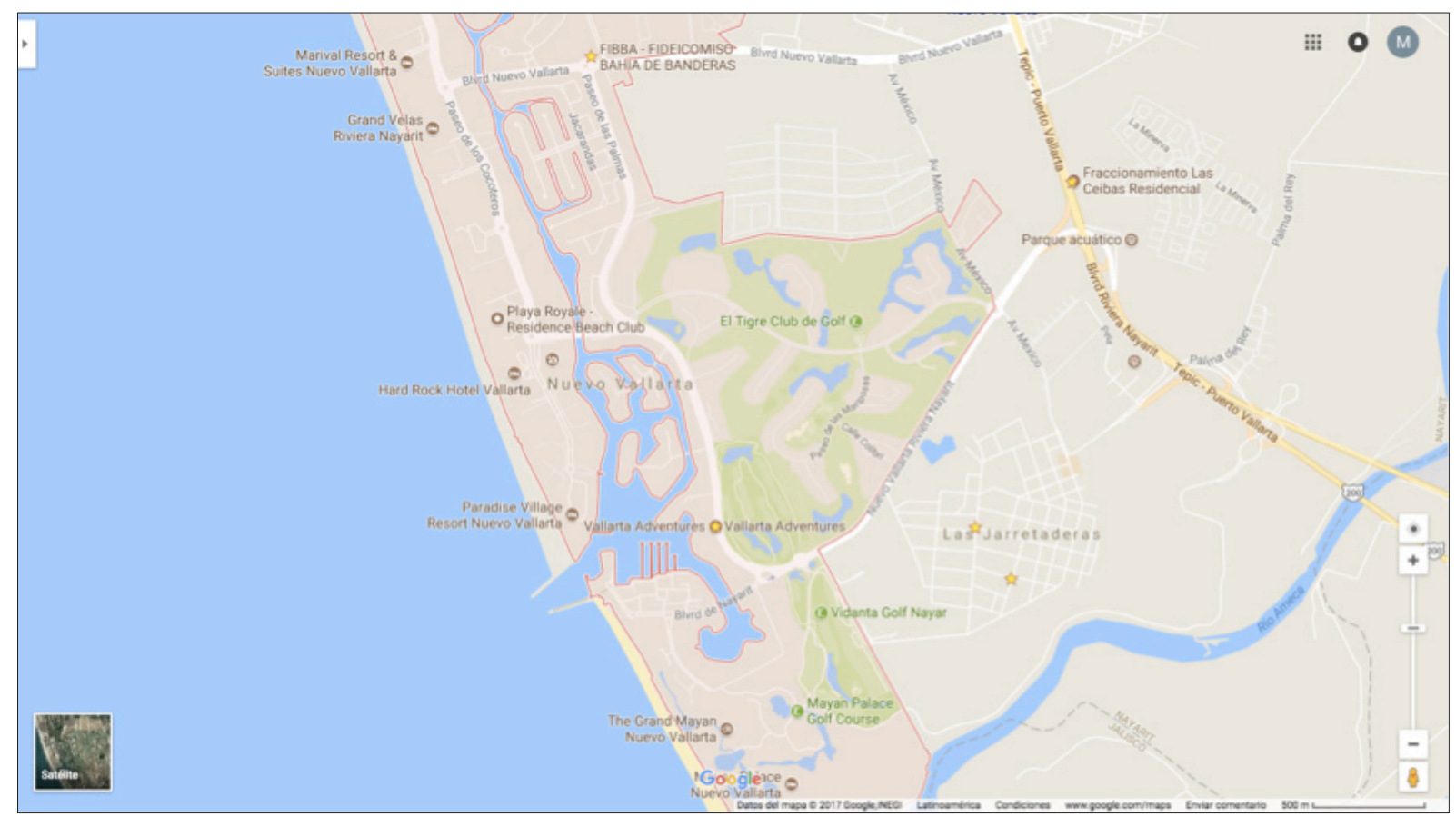

Mapa 3. Ubicación de Nuevo Vallarta

Fuente: https://goo.gl/maps/NXVX26b6erP2

Nuevo Vallarta, localizado en la parte suroeste de Nayarit (Mapa 3); pertenece al Municipio de Bahía de Banderas, el cual tiene su cabecera municipal en el pueblo de Valle de Banderas. Se localiza a $150 \mathrm{~km}$ de la Ciudad de Tepic, y a unos 10 minutos de Puerto Vallarta, Jalisco. Cuenta con un área total de 1973 hectáreas, 7 kilómetros de costa en el Océano Pacífico, y aproximadamente 3 kilómetros de anchura a todo lo largo. Al sur colinda con el río Ameca y la población de Jarretadera, al oriente con la carretera Tepic-Puerto Vallarta y las poblaciones de Mezcales y Mezcalitos, al norte con Bucerías. La zona turística se compone por terrenos pertenecientes a los fraccionamientos turísticos de Nuevo Vallarta y Flamingos, y a los ejidos de Bucerías, Jarretadera y Valle de Banderas en un área aproximada de 300 hectáreas. Hoy son el mercado turístico más importante en la región y receptor de un turismo de altos ingresos, pues tanto el Estado como los inversionistas privados, se han empeñado en ello.

Inicialmente las empresas dominantes en infraestructura turística en el área serían Marival Group y Paradise Village Group. La primera fundada en 1984 por el Senador Canadiense Pietro Rizzuto, quien inició operaciones bajo el concepto de Condo-Hotel convirtiéndose en uno de los principales propulsores del desarrollo de 
Nuevo Vallarta al introducir al mercado turístico el concepto "Todo Incluido" (All Inclusive) en 1987. La segunda surge con la empresa Nuevo Vallarta S. A., representada por Graciano Sovernigo quien inició tratos de adquisición de derechos el 24 de febrero de 1989 al suscribir, con varias secretarías de gobierno, el acuerdo y convenio que dejaba sin efecto el contrato del FIBBA. En el año 2004, la empresa fue liquidada, aunque siguió siendo de la misma familia, pero con otra razón social.

Hoy, el grupo dominante en cuanto a infraestructura turística es el Grupo Vidanta, antes Mayan Palace, nombre con el cual la cadena hotelera duró más de 20 años. El cambio de razón social, se cree fue debido a un enfoque reciente de incluir parques temáticos en sus instalaciones en asociación con la empresa canadiense de entretenimiento mundial Cirque Du Soleil. Su oferta de alojamiento, creció de manera descomunal. En 2012 contaba con 2222 habitaciones y para 2015 se calcularon alrededor de unas 3 mil. Hoy es propietario de aproximadamente 15 edificios y se asegura que la construcción de más cuartos, continúa.

A finales del 2014, Vidanta junto con el Cirque Du Soleil anunciaron el proyecto del Parque de Atracciones Temático. Entre sus atractivos: un auditorio abierto con capacidad de 3 a 5 mil personas para las presentaciones del circo, un parque acuático y uno ecoturístico. Este plan, pretende incorporar el polígono denominado Isla de los Pájaros bajo el discurso de proteger el ambiente de la depredación, al cual sólo se podrá acceder desde el hotel ${ }^{32}$. La pretensión no ha sido materializada gracias a la oposición de grupos residentes de Nuevo Vallarta y de la zona.

El tipo de turismo llevado a cabo en Bahía de Banderas y Nuevo Vallarta, establece nuevos sistemas de relaciones sociales y cambios estructurales en todos los estratos de la vida social. Negativamente, estos son reconocidos con altos costos sociales para las poblaciones involucradas, definidas de tres maneras principales: desarraigo, ruptura del tejido social y la privación de sustento de los actores locales ${ }^{33}$, aspectos que representan los ámbitos político, cultural y económico tras el proceso de desterritorialización. Precisamente estos ámbitos muchas veces son cuestionados como aptos para continuar con la implementación de la actividad turística en este contexto pues demanda en primer lugar la separación de comunidades de su territorio seguido de transformaciones territoriales profundas y una serie de afectaciones ambientales negativas. Estos son expresados en dos ámbitos, sociales y físicos.

De manera general, algunas investigaciones ya realizadas bajo el presente objeto de estudio, plantean una serie de impactos sociales como son: migración, saturación de espacios, aumento de subempleos y empleos informales, déficit en vivienda y servicios, dependencia económica a una sola actividad, despojo y desplazamiento de espacios dedicados a la agricultura, pesca y ganadería, reubicación de las poblaciones originarias y ruptura de patrones socio-culturales, entre otros.

Sin embargo, la visita de campo ha permitido obtener información de manera escrita y oral a través del diálogo con algunos informantes clave, ejidatarios residen-

32 Forbes México 2014; La Jornada 2017.

33 Azuela, Herrera y Saavedra 2009. 
tes del área estudiada, lo cual permite dar cuenta hasta este momento, de un panorama sobre la situación social a partir de la transformación territorial sufrida con el proceso de internacionalización del destino turístico. La propuesta teórica en la que se basan estos hallazgos, especifica de manera precisa las dimensiones de la desterritorialización: económica, política y cultural complementadas entre sí, tomando en cuenta al territorio no solo como espacio físico sino ejercicio de relaciones sociales con y dentro de este. Por esta razón, se hará un esfuerzo por ubicar dichos hallazgos en cada una de las dimensiones referidas para poder mostrar una realidad más clara y cercana a la crítica del modelo turístico hegemónico materializado con la evolución de Bahía de Banderas y el megaproyecto de Nuevo Vallarta.

El desarrollo turístico ha traído empleo, cuestión que no puede ser negada, sin embargo, bajo los estándares del salario mínimo, empleos temporales con extensas jornadas, sin seguridad social o prestaciones de ley, entre otras cuestiones. Cuando recién empezaron a entrar los primeros hoteles, el acceso al trabajo era más fácil y con menos requerimientos, pero hoy se ha complicado. Por ejemplo, se exige un mínimo de uno o dos años de experiencia. Los empleos actuales, en empresas de recreación encargadas de ofrecer tours, así como los empleos en hoteles, no son seguros, pues dependen de la temporada turística bajo contratos temporales. Al ser temporada alta, se requiere de mayor personal, pero cuando es baja, muchos trabajadores no son contratados, teniendo que buscar otras fuentes de vida. "Los salarios ofrecidos, honestamente no alcanzan para vivir" -Carlos Pérez-. O, por ejemplo, los meseros, donde el $90 \%$ de su salario son las propinas, bajo jornadas laborales extensas. En distintos casos, las personas se ven obligadas a pedir préstamos que por años han estado pagando, pues las entradas económicas son mínimas, en comparación con los gastos requeridos para vivir, los cuales se encarecen cada día, sin olvidar la presencia de situaciones inesperadas:

"Me endeudé porque mis dos hijas se enfermaron y tuve que pagar operaciones, hospital, etc. Mi empleo como vendedora no me da oportunidad de tener un servicio de seguridad social para sufragar ese tipo de gastos. Fueron alrededor de 100 mil pesos, además de la renta del local y las mensualidades de un carro, me fui a la quiebra y entonces pedía préstamo sobre préstamo para salir. Aún debo el local anterior, pero hay voy pagándolo. De hecho, un tiempo me dediqué a vender a los hoteles" ${ }^{\prime 4}$.

"Perdí todo en unos negocios donde invertí, tuve deudas, comía arroz y vivía con 10 pesos al día, literalmente. Me compraba dos pastas y un cuadro de jugo de tomate, lo mezclaba en la charola y eso comía 3 veces al día. En Vallarta Adventures, mi salario debería ser de 12 mil pesos, pero es muy variado, las últimas quincenas no han rebasado los 3 mil pesos. Depende mucho la demanda de turistas. Los nacionales son escasos pues para un mexicano que gana poco, los tours son costosos, por ello la mayoría de los clientes son extranjeros. Con las propinas llego a sacar entre 5 mil y 10 mil pesos al mes, pero es muy incierto. Además, mucha gente no puede dejarte, porque quizá han ahorrado todo un año para venir de vacaciones y no pueden despilfarrar el dinero, lo traen medido. Aunque no lo considero un ingreso malo, no alcanza para vivir pues aquí la vida es cara. En este momento tengo una deuda entre 300 y 400 mil pesos que debo en tarjetas, préstamos y el carro, mis estudios quedaron truncos" ${ }^{\prime 35}$.

34 Estela Martínez. Comunicación personal.

35 Carlos Pérez. Comunicación personal. 
"El trabajo actual en Vallarta Adventures, demanda mucho esfuerzo físico, a veces ni te da tiempo para comer" “... Antes de trabajar en Vallarta Adventures, trabajé 6 años en hotelería, desde áreas públicas, toallera, después en cocina, de cajera a vendedora, luego en el área de recepción. Pero es un trabajo muy demandante, 10 horas, sólo llegar a dormir y trabajar los fines de semana. 7 años trabajé para Vidanta, pero ya no me dejaron crecer además de que nació mi hijo..." ${ }^{36}$.

Por otro lado, la gente originaria de los pueblos, en especial Jarretadera, ubicado junto a Nuevo Vallarta, reconoce la creación de empleos, así como el desarrollo urbano inicial tras la desterritorialización con la expropiación de sus tierras, es decir, el programa social de regeneración de los poblados. Más aún, en cuanto a sus necesidades, autoridades y hoteleros no destinan ningún tipo de utilidad o ingresos para el pueblo, como se prometió en los acuerdos de creación del FIBBA, donde los campesinos y ejidatarios, al ser socios, tendrían beneficios con la compra-venta de las tierras y el desarrollo de empresas turísticas: "No ha llegado beneficio alguno de la creación de los hoteles del Mayan (Grupo Vidanta), ninguno hace nada por el pueblo, ni el gobierno ni las empresas" -Liz Castillo-. Incluso, existe temor por parte de los poblados junto a Nuevo Vallarta, Jarretadera y Mezcalitos, debido al interés corporativo y estatal de ampliar el enclave turístico para la creación de un parque temático en manos de Cirque du Soleil y Walt Disney, compañías estadounidense y canadiense respectivamente.

Una de las formas como operan estos grandes complejos turísticos, es promover la venta de membresías sobre servicios de alojamiento aún inexistentes, utilizando el dinero cobrado para empezar a construir En otros casos, los proyectos quedan truncos o, de hecho, nunca se inician. En el caso de Nuevo Vallarta, un hecho que sorprende a la población, ha sido el aumento descomunal de los servicios de alojamiento, entre hoteles y segundas residencias. Se cree que este hecho no sería posible sin la presencia de ciertos intereses, la participación del gobierno e incluso de actividades delictivas como narcotráfico, prostitución, lavado de dinero y otros, donde la inversión en servicios turísticos resulta una vía legal para "blanquear dinero sucio".

El turismo representa una plusvalía y un negocio para los inversionistas, pero en ningún momento las poblaciones desterritorializadas, se ven beneficiadas, lo cual, ha traído inconformidad por parte de la población. La gente que vivía de la pesca, por ejemplo, mantiene una pequeña cooperativa, pero la propiedad privada de las playas, les ha negado ya el acceso para sus embarcaciones. Hay otros casos donde las personas llegan a rentar su casa para poder vivir. Tal fue la experiencia en el ejido de Jarretadera (entre 2007 y 2010), con la llegada de migrantes provenientes de Chiapas mayoritariamente, donde se vivió un deterioro considerable en el poblado a partir de situaciones de violencia, saturación, abaratamiento de la mano de obra local y arrendamiento en condiciones deplorables:

"Vino mucho hombre solo, había gente durmiendo hasta en las azoteas, banquetas y patios. Había mucho conflicto... seguido se navajeaban... gente muy agresiva. Incluso había suicidios y como mujer, sentías mucho riesgo. Muchas personas vivían en condiciones de-

36 Emilia Reyes. Comunicación personal. 
plorables, pues incluso se rentaban casas aun estando en obra negra. Era contradictorio, la misma gente se quejaba, pero ellos mismos propiciaban la situación. Las escuelas a reventar, el centro de salud no se daba abasto. Había quejas, pero ninguna acción para enfrentarlo. La gente aprovechaba cobrar para trasladar a los migrantes a las zonas de construcción. Llegaban montones de camiones de Chiapas, a veces hasta ni agua había"37.

A pesar de todo ello, algunos de los entrevistados encontraron positivo, la regeneración de los poblados con la creación de clínicas, vías de acceso, centros de salud, escuelas, la instalación de servicios de luz, gas, agua y drenaje, así como la construcción de sus casas. No obstante, esto no es más que la estrategia de mediación entre el Estado y la población para privatizar el territorio ejidal y abaratarlo a grupos turísticos privados, cuyo fin es imponer legalmente un nuevo uso del territorio, es decir, el turístico a través de un modelo hegemónico que permita reproducir los valores capitalistas: acumulación, maximización y concentración monopólica de las ganancias. Esta nueva dinámica, donde el turismo es visto como generador de ingresos, ha traído efectos sobre el territorio en sus ámbitos político, económico, cultural y natural.

Antes de la expropiación de las tierras, la población era completamente libres de satisfacer sus necesidades de vida haciendo uso de los bienes naturales dentro del territorio: alimentarse, trabajar y recrearse. Como se dijo en el primer apartado, ir en familia a pasear al mar o al río para satisfacer su necesidad de alimentación, resultaba ser una típica tradición y costumbre de la población. La alimentación actualmente, es dispuesta por el comercio, y ha perdido el contexto y significado que tenía esta actividad, aunado a la mala calidad a partir de la producción industrial de los alimentos.

Otros bienes consumidos, son desechables, de poca durabilidad y perecederos, al punto de que las personas se ven forzadas a consumir más bienes en menor tiempo, gracias a una explosión de publicidad y propaganda para adquirir estos, aun cuando no resulten necesarios. Estos aspectos fundamentales, constituyen la reproducción de la sociedad de consumo.

Dedicarse al campo, como necesidad primaria, constituía todo un rito. Actualmente la población está prácticamente negada al uso de los recursos marítimos, porque la mayor parte de la extensión del litoral es ya de propiedad privada en manos de los consorcios hoteleros, donde domina el grupo Vidanta. A este respecto, informantes clave del poblado de Jarretadera, hacen mención de la existencia de una entrada hacia las playas a través del mismo pueblo, donde algunas veces pueden acceder. Sin considerar esta, no hay otras posibilidades de acceso, y más bien para disfrutar de estas, forzosamente habría que hospedarse en los hoteles. Lo cual resulta casi imposible, pues los precios redundan entre los 2 y 8 mil pesos la noche. Esta prohibición ha hecho que una parte de la población se manifieste haciendo un llamado a las autoridades, los hoteleros y al expresar su descontento a través de redes sociales.

37 Ibíd. 
"Un día llegamos a la playa, y ya no se podía pasar, de repente cerraron además de que habían destruido el manglar, incluso para nosotros fue un hecho traumático... no nos dejan pasar y acceso libre ya no hay. Está cerrado y privatizado"38.

"Ahora ya no hay acceso a la playa, tienes que irte al hotel. Ya cerraron el río, ya cerraron to$\mathrm{do}^{\prime \prime 39}$.

La llegada de extranjeros a la zona, introdujo nuevas prácticas culturales como el surf, el béisbol o futbol. En cuanto celebraciones, se conservan en algunos pueblos, el 20 de noviembre, el 16 de septiembre o 1 de mayo como el día de la dotación de las tierras de los ejidos. Predomina la celebración de los 100 años de Vallarta como ciudad y puerto, o de la creación de la marca "Riviera Nayarita", aunque basadas en una ideología de consumo a través de grandes campañas de publicidad y mercadotecnia. Esto, nada tiene que ver con las antiguas peregrinaciones, fiestas con carros alegóricos, jaripeos, danzas, entre otras cosas que se hacían. El megaproyecto de Nuevo Vallarta, es un producto ausente de relación con la cultura autóctona o incluso mexicana. En algunos pueblos como San Juan de Abajo, desde el periodo del último presidente municipal, se empezaron a realizar una serie de bailes, con grupos musicales provenientes de otros pueblos.

La mayor parte de la población, quienes no son considerados de la tercera edad, trabajan en los hoteles y debido a las jornadas laborales tan largas, pueblos como Jarretadera o Mezcalitos, suelen quedarse vacíos durante el día. Se puede notar una ausencia importante de personas, debido a esto. De los pueblos ubicados más hacia el monte o la zona del Valle, mucha gente joven también trabaja en hotelería, teniendo que desplazarse desde sus pueblos a la zona costera y demás áreas turísticas. En el caso particular de la población de Mezcalitos, esta se encuentra conformada por una minoría de población local y en mayoría, migrantes de otras partes que llegaron para ser empleados en la construcción. Ahora, se dedican a vender en las playas diferentes productos (ambulantaje) y son llamados "playeros". Muchos de estos, no tienen la suerte de poder desempeñar esta actividad ya que los hoteles les prohíben la entrada.

Por un lado, se considera que la forma de vida ha cambiado muchísimo gracias al desarrollo traído con la actividad turística, siendo mejor a como se vivía antes. Por otro, es posible notar un cambio muy fuerte en las costumbres y el modo de vida, pues de ser dueños y propietarios libres, pasan a ser empleados de los servicios turísticos con importantes pérdidas de lo cultural:

"Dejamos de ser los dueños del lugar, ya no podemos acceder a la playa como antes, que nos íbamos a pie en carretas con todo y la familia, ya no se puede. Ahora está restringido, con vigilancia. Antes podías galopar a la playa sin que nadie dijera nada. Teníamos gran libertad y teníamos el río Ameca que nos daba mucho pescado, camarón, no estaba contaminado como ahora. Hoy la tierra es para la producción de cosas." ${ }^{\prime 4}$.

38 Ibíd.

39 Liz Castillo. Comunicación personal.

40 Alberto Hernández. Comunicación personal. 
La región de Bahía de Banderas, actualmente se conforma de 12 ejidos y una comunidad indígena, no refiriéndose a la existencia de indígenas sino una extensión territorial con una distribución y organización de la tierra, donde todo es de uso común, a diferencia del ejido donde cada quien tiene su parcela con un tramo de uso común. Con la nueva ley, se empezó también a parcelar para la conformación de esta zona en ejidos, aunque siguen dependiendo de la comunidad.

La organización social ejidal se mantiene en comunicación a través de juntas realizadas cada último domingo del mes. En ellas los ejidos se reúnen para ver las problemáticas de unos y otros a manera de compartir sus experiencias, únicamente con las personas dueñas de parcelas en la región del Valle pues la mayoría de tierras colindantes al mar han sido adquiridas por el gobierno y vendidas a manos privadas. Los comisariados ejidales permanecen tres años con ese nombramiento, lo que permite dar cuenta de la conservación de esta forma política.

Ser ejidatario, implicaba dar una contribución monetaria, a través de la venta de terrenos o la producción agrícola. Había más dinero antes, debido a esto, se aportaba cada dos meses o uno o también se cobraba por reconocer los documentos de título de propiedad y así de toda venta se obtenía algún aporte económico. Al final del periodo de cada presidente ejidal, este podía decidir sobre el uso del dinero captado, ya sea para remodelación de la casa ejidal u otra cuestión. En otro caso, repartir el dinero entre todos los ejidatarios. Esto no era lo común, sin embargo, en un periodo, se decidió repartir el monto total del dinero reunido, entre cada uno de los integrantes. La aportación económica actualmente, ya no es una práctica habitual en todos los ejidos.

Hoy existen alrededor de unos 300 ejidatarios, de los cuales algunos siguen sembrando en sus parcelas, por ejemplo: sandía, frijol, sorgo, maíz, calabacita, tomate de cáscara. La sucesión de derechos sobre la tierra, es posible hasta el fallecimiento del actual dueño y una vez que esto sucede, los trámites deben llevarse a cabo hasta la ciudad de Tepic ante la aún existente Reforma Agraria.

A pesar de conservar esta forma política sobre el territorio, las relaciones sociales se han fracturado, sobre todo de la región del litoral: “... la gente aquí difícilmente se junta para algo... el pueblo está dormido y no le interesa..."41. Esta declaración va en relación en el caso por ejemplo del poblado de Jarretadera, donde las personas llegan a tener conflictos de inundaciones, estancamiento del drenaje y otros problemas, sólo unos cuantos externan esto ante las autoridades, pero al no contar con más apoyo, no son escuchados ante sus necesidades. Existió un caso donde la población de Mezcalitos, un pequeño poblado y el segundo más cercano al desarrollo de Nuevo Vallarta, se levantó con machetes y palas en oposición a la construcción de la vía de acceso al pueblo, la cual pretendía ser ubicada en una zona muy lejana. La gente estuvo en desacuerdo pues un acceso tan retirado del acceso a vías de comunicación y transporte, les causaría dificultad para trasladarse a sus espacios de trabajo. Es muy probable que las intenciones de esto fueran porque no se deseaba la

41 Liz Castillo. Comunicación personal. 
cercanía de la entrada al pueblo, con el complejo turístico Nuevo Vallarta. Para introducirse a este, hay una vía por la cual también está el actual acceso al poblado. Su conformación poblacional, está conformada por migrantes de Veracruz, Querétaro y Oaxaca principalmente, los llamados "playeros".

Por otro lado, ejidatarios y gente de los pueblos que ven en la venta de tierras, un negocio y, otros, que se niegan a permitir la expansión del megaproyecto de Nuevo Vallarta. A este respecto, algunos pobladores -según enviados por el grupo Vidanta- han invitado a otros a venderles algunos terrenos o incluso todo el ejido. Sin embargo, esta acción podría traer como consecuencia, la desaparición total del pueblo para la expansión de servicios turísticos que sólo pueden pagar unos cuantos, aunado a la privatización, transformación del paisaje en un estilo americanizado y la reubicación de la población sin un plan de ordenamiento adecuado para ello.

Se mantiene hasta el momento, una situación tensa debido a la construcción de un túnel para trasladar a los turistas directamente desde el aeropuerto hasta el complejo turístico, pero de manera escondida y con el desconocimiento del pueblo. Este no puede verse visible a simple vista, fue estratégicamente hecho y "por debajo del agua". Al darse cuenta de ello, existe una preocupación pues podría causar fuertes inundaciones al poblado de Jarretadera. Y a pesar de pedir respuesta de las autoridades, estas no han dado la cara.

En la búsqueda de obtener algún beneficio, el pueblo se organizó para realizar un tianguis turístico, el cual pudiera generar ciertos ingresos para el pueblo a través de la visita de turistas, sin embargo, el gobierno se los negó, a saber:

“... No quieren el progreso para la gente sino más bien para expandir Nuevo Vallarta... para ello tendrían también que quitar chozas de gente que vende pescado sarandeado, argumentando que esto contamina... o que el pueblo acorrienta el producto, se ve mal. Es obvio que ahí hay intereses, el gobierno inmiscuido, narcos." ${ }^{\prime 2}$.

En cuanto a las afectaciones de tipo natural, de la mano con los efectos sociales, la población originaria identifica la contaminación en los mares y océanos, la desaparición de ecosistemas, pérdida de la biodiversidad tanto terrestre por la deforestación como marina, degradación del suelo, transformación del paisaje tanto natural como social, el alto consumo de recursos energéticos, pérdida de manglares, esteros y humedales a partir de su tala inmoderada que a su vez ocasionan otros impactos como la degradación de las playas naturales, la vulnerabilidad ante ciclones y huracanes $^{43}$, aguas negras no tratadas, entre otros. En el caso particular del río Ameca, resulta ser el principal recipiente de las aguas negras de la planta de tratamiento del poblado de Las Juntas supuestamente tratada pero incluso plantas de Vallarta descargan también en este sus residuos; del Puerto ubicado en el corredor turístico y de los consorcios hoteleros próximos al río. Siendo que este bien natural, solía ser una de las principales fuentes de alimentación y recreación de las poblaciones campesinas.

42 Ibíd.

43 Real, Olivarría y Madera 2010. 
El agua potable no escaseaba, la planta tratadora de agua resultaba adecuada y no existía la saturación de vehículos, problemas que actualmente si son visibles. La población aumentó desproporcionalmente entre los turistas que se han quedado a vivir, visitantes temporales, población migrante para la construcción y otra más para la operacionalización de los servicios turísticos.

El área natural donde ahora se encuentra Nuevo Vallarta, era un estero llamado "El Chino", cual fue devastado. De acuerdo con un informante clave, existen algunas áreas protegidas que han conservado como pulmones. Pero de estas, ya se han destruido varias, a pesar de las promesas de conservarlas. Se han construido casas sobre esteros, manglares y humedales. Poca es la gente que los conserva, otra más ve estos ecosistemas como hierba salvaje, inservible y los destruyen. Sin olvidar también la afectación ocasionada por las embarcaciones. Nada de esto es considerado a pesar de la importancia ya conocida de los manglares, cuyo principal objetivo es detener otros procesos naturales amenazantes como los huracanes y ciclones, además de ser cuna de diversas especies marinas que mantienen el equilibrio de la zona. Toda el área donde se establecen los hoteles del grupo Vidanta, era manglar. Queda muy poco del ecosistema original y a pesar de la reforestación, se considera, ello no compensa la degradación actual. Las construcciones de mansiones, muelles, casas y demás, continúa, al parecer con mucho ímpetu de expansión y crecimiento urbano, turístico y habitacional. Muchos de los hoteles se encuentran en zonas de riesgo.

En resumidas cuentas, las afectaciones ambientales en conjunto, son visibles ante una importante invasión de ríos y áreas comunes, debido a las nuevas generaciones y la migración; la falta de servicios como el agua potable, la planta tratadora de agua que resulta insuficiente, la saturación de automóviles, la pérdida de usos y costumbres tradicionales, la desaparición de especies como la guacamaya, loros y el venado; un nuevo estilo de vida basado en el deseo del modo de vida de las sociedades capitalistas; endeudamiento producto de salarios tan bajos, la fractura en la organización ejidal de zonas importantes de la región, la confrontación de los que ven al turismo como una trasformación benéfica y los otros, negados a la expansión de la misma bajo una dinámica inmobiliaria; la inconformidad social ante la indiferencia del gobierno con respecto a diversas necesidades y la destrucción de ecosistemas que más tarde generarán otros conflictos. Los hallazgos de la actual investigación, llevan a profundizar en la importancia de una participación más activa en apoyo de la lucha por la conservación territorial para la reproducción de la vida contra a explotación de bienes naturales y humanos para el enriquecimiento de grupos privados, siendo esto último lo que atenta contra la vida. Y por esto mismo, se ahonda en el estudio crítico de la actividad turística para repensar su desenvolvimiento en los litorales mexicanos.

\section{Conclusiones}

El modelo teórico-metodológico empleado, permitió distinguir entre las diferentes etapas necesarias para que el sistema de producción mundial funcione. De manera 
similar, los procesos de penetración, desterritorialización y acumulación, se presentan para dar lugar a las formas extractivas del capital como es la minería, los sistemas agroalimentarios, de biotecnología, urbanización e infraestructura, recursos energéticos e hídricos, así como el turismo, siendo este último una de las formas actuales de acumulación capitalista. Así mismo, se ha encontrado que, dentro de los procesos aquí presentados como consecuentes, existe una interrelación de tres actores fundamentales: el Estado, el capital (en este caso turístico) y las poblaciones locales afectadas.

En el proceso de penetración puede verse una mayor participación del capital, el cual presiona a los Estados-nación periféricos para la apertura de sus fronteras ante nuevas formas extractivas. En el caso de México, se establece la actividad turística como pilar económico prioritario, haciéndose necesaria la conformación de instituciones, la creación y reestructuración de políticas y leyes, en conjunto con acciones para poder legitimar un modelo turístico hegemónico dirigido a satisfacer una demanda internacional, donde su principal tarea es preparar el terreno para la llegada de firmas trasnacionales de servicios turísticos. Las principales políticas son aquellas dirigidas hacia la desregulación de empresas y servicios paraestatales, privatización de la tierra y el abandono de apoyo hacia las actividades primarias, entre otras.

En cuanto a la etapa de desterritorialización, el Estado es el principal participante junto a las poblaciones campesinas. Este proceso resulta ser la etapa de aplicación en lo establecido política e institucionalmente en el proceso de penetración. Se materializa la acción de despojo en la forma particular de expropiación, legitimada bajo el recurso de utilidad pública para privatizar el territorio como reservas de área turística y establecer polos de desarrollo en conformidad con la política de internacionalización del turismo. Aquí el Estado, actúa de manera directa para expropiar las tierras propicias para el desarrollo de un modelo de sol y playa, donde al mismo tiempo acude a una estrategia de dominación y mediación para evitar el antagonismo de las poblaciones afectadas. Dicha mediación fue materializada con programas sociales de apoyo al campo, urbanización de los pueblos y la conformación de un Fideicomiso en apoyo a los ejidatarios afectados tras la expropiación, quienes recibirían parte de las utilidades obtenidas del desarrollo turístico llevado a cabo en las tierras despojadas.

En el proceso de acumulación, el Estado se deslinda de su responsabilidad jurídica y política para con los afectados; la población local con toda una serie de transformaciones sobre sus formas de vida, insertos en la producción de servicios con diversas carencias y necesidades que los gobiernos ignoran y más bien, un panorama positivo para la expansión de desarrollo turístico en la zona, donde sus necesidades de acumulación de capital son atendidas por el Estado, dejando ver una situación de segregación, exclusión, privatización y marginación que divide el megaproyecto turístico de las poblaciones locales afectadas. Y donde los hallazgos sobre las afectaciones ambientales, se proponen como la aportación más importante de este es- 
tudio, a manera de exponer otra realidad distinta del sólo hecho de la acumulación dineraria para los empresarios turísticos y el apoyo del Estado a estos.

De esta manera, el desarrollo de un modelo turístico hegemónico, deviene de los mismos principios del sistema económico capitalista. El sistema-mundo ha encontrado en esta actividad, las posibilidades de hacer circular capitales, la generación de plusvalía, concentración de ingresos gracias al establecimiento de cadenas turísticas que acaparan los servicios necesarios para el turismo: alojamiento, transportación y entretenimiento principalmente.

Al establecerse en países subdesarrollados donde los costos de producción son más bajos en comparación con la producción a escala mundial de otros países, maximizan sus ganancias. Además, existe una cierta tendencia hacia la monopolización de los servicios, con el fin de garantizar la concentración de los ingresos. Cada vez menos grupos privados van concentrando cada vez mayores ganancias.

Sin embargo, la reproducción del sistema capitalista y sus formas extractivistas, requiere de la aprobación de los gobiernos locales para establecerse en los espacios geográficos de su interés para la acumulación de capital. En otras palabras, los Estados-nación de países tercermundistas, debido a diversas situaciones como la ubicación geográfica que privilegia la existencia de ecosistemas diversos y primordialmente su posición histórica dentro de la división internacional del trabajo como proveedores de materias primas ante la falta de un sistema de producción a escala global, crea una posición de dependencia frente a los préstamos amparados por naciones imperialistas y organismos económicos internacionales, siendo parte de las circunstancias directas e indirectas que llevan a adoptar los estatutos de un sistema mundial.

México, se posiciona dentro de la oferta de producción primaria en la división internacional del trabajo, con una historia donde ha prevalecido la dominación de distintos imperios, el saqueo, la explotación, con un sistema político corrupto y donde han dominado las pequeñas clases burguesas a favor de las clases dominantes mundiales.

En la actualidad, se marca un favorecimiento a la reproducción del sistema capitalista y sus formas extractivas, desde la definición de nuevas políticas económicas internacionales. Entre ellas, se establece a la actividad turística por su capacidad generadora de ingresos, y por lo que se exige sea incorporada a través de una política nacional con el fin de satisfacer dichos flujos económicos hacia el exterior. Así es, como el Estado mexicano adopta la política de internacionalización del turismo, materializada con los Centros Integralmente Planeados o "polos de desarrollo" como la Bahía de Banderas. Esta se ha promocionado bajo la marca de Riviera Nayarit y la oferta de diversos desarrollos turísticos privados dirigidos a una demanda de altos ingresos.

Las afectaciones de este tipo de turismo, son preocupantes, pues se observan coincidentemente en los destinos de litoral donde se han llevado a cabo. En la región de Bahía de Banderas y específicamente el enclave de Nuevo Vallarta, ha causado 
una serie de afectaciones naturales y sociales que definen lo económico, lo político y lo cultural:

- La pérdida de acceso a los bienes naturales: mar, río Ameca, reserva natural

- El cambio de alimentación derivado de lo anterior, pues las personas ahora consumen los productos industrializados y ofertados en su mayoría por cadenas comerciales

- El abandono de actividades tradicionales como la cocina, ir de pesca, la convivencia en familia

- Las actividades productivas en su mayoría han desaparecido, pocos son quienes siguen cosechando para el autoconsumo porque se ha dejado de apoyar la producción en el campo

- La población se ha inmerso en una dinámica del trabajo asalariado, ocupando la mayor parte de su tiempo en los empleos ofrecidos por los servicios turísticos. Existe un desprendimiento de la convivencia familiar y de las actividades antes llevadas a cabo derivado al abandono de la vida en y con la tierra

- En su necesidad, y debido a que los sueldos no son suficientes, recurren a los préstamos bancarios, cayendo en el endeudamiento por muchos años. Por un lado, las condiciones de vida son limitadas, pero por otro, son presionados para reproducir la cultura de consumo y copiar el estilo de vida de las sociedades capitalistas.

- Existen algunos fraccionamientos dentro de la región llamada "El Valle", donde se ha establecido en mayor medida, una población migrante de otras regiones y Estados, que llegaron para insertarse en el empleo de la construcción y operación de servicios turísticos. Las condiciones de estos fraccionamientos presentan diversas carencias que no son atendidas por el gobierno. Múltiples casas de mala calidad, descuidadas, sin seguridad, de dimensiones pequeñas y alejadas de los poblados.

- Las formas de organización social, se han perdido considerablemente debido al abandono de las actividades primarias en algunos ejidos, sobre todo los que se encuentran a mayor proximidad del litoral, aunque se sigue eligiendo a su presidente ejidal, las decisiones en cuanto a planeación y ordenamiento territorial son tomadas por el gobierno local debido a la expropiación de las tierras. Algunos otros ubicados del lado contrario hacia el monte en la región llamada "El Valle" se llegan a hacer juntas ejidales para compartir experiencias, más que la organización tradicional comunitaria que con base en la producción primaria, se juntaban ingresos para el beneficio y las necesidades de los ejidos.

- Se ha negado a la población de este ejido, la realización de un tianguis turístico para apoyarse económicamente y atender ciertas necesidades. Por lo que la población se encuentra inconforme y exigiendo al gobierno la aten- 
ción de sus necesidades (drenaje, inundaciones, transporte, contaminación y basura, entre otras)

- Algunos ejidatarios de este poblado, han vendido tierras al grupo Vidanta para que este se expanda, e incluso han invitado a otros a vender. Hasta ahora existen esas dos posiciones respecto a las tierras.

En el aspecto natural:

- Han desaparecido la población marina en el río Ameca producto de una fuerte contaminación;

- Las descargas de aguas negras son vertidas al río y por tanto al mar. A pesar de la existencia de una planta tratadora, no resulta suficiente para la cantidad de desechos generados por los poblados y los complejos turísticos;

- La reserva natural cerca del río Ameca entre el límite de los estados de Jalisco y Nayarit, ha sido concesionada al grupo Vidanta, por lo que la población ya no tiene acceso a esta ni al río ni al mar en lo que va del desarrollo de Nuevo Vallarta;

- Se han perdido gran parte de los manglares y humedales en la zona que comprende el megaproyecto de Nuevo Vallarta, la empresa aparentemente maneja una política de conservación ambiental e incluso la caracterización "Blue Flag" como reconocimiento por la excelencia en el manejo ambiental. Sin embargo, este mismo estatuto es violado al permitir la ampliación y construcción de más residencias, muelles y servicios marinos.

- Existe un paisaje en condiciones de marginación, exclusión y segregación entre el límite del complejo turístico de Nuevo Vallarta y el ejido de Jarretadera, donde incluso puede verse terrenos ya cercados y bardeados en los límites que separan al ejido y el río Ameca, cerrando el acceso hacia éste.

Es importante decir, que el modelo teórico-metodológico aplicado, por un lado, ayudó a definir las dinámicas capitalistas para el desarrollo de la actividad turística, definidas para el presente caso de estudio, en función de etapas históricas particulares. Los procesos que se explican tienen un lugar y tiempo definido en el que se llevan a cabo otros procesos necesarios para la dinámica que le sigue. Este mismo modelo, puede ser visualizado en diferentes áreas de estudio, sobre todo zonas geográficas con las características requeridas para establecer un modelo turístico hegemónico, definido aquí como el modelo de sol y playa, a los cuales se hace referencia con enclaves turísticos o megaproyectos. Cabe resaltar que, por el corte de estudio se profundiza en el interés de mostrar las afectaciones sociales de las poblaciones que son desterritorializadas bajo la presión del capital internacional en dominio de un sistema-mundo y forzadas, unas veces de manera legal y otras ilegalmente por el Estado, para favorecer intereses privados a través de relaciones de poder; sin que esto signifique el estudio por separado de los aspectos tanto natural como social. Más bien, estos dos aspectos no pueden separarse porque precisamente las transforma- 
ciones territoriales se definen en función de la relación hombre-naturaleza aunado a que, el aprendizaje y contribución de conocimiento de las ciencias ambientales, se verá reflejado en el estudio conjunto de las relaciones del hombre individual y social con su entorno físico pues de ello depende su supervivencia.

\section{Bibliografía}

ANDRADE ROMO, Edmundo. [entrevista] Por Mariel, Massé, [Contribución a la al proceso histórico de transformación en Bahía de Banderas], Desterritorialización en Bahía de Banderas y Nuevo Vallarta. Jalisco: Universidad de Guadalajara-Centro Universitario de la Costa, 2016.

ÁNGEL MONTIEL, Pavel del. Despojo e ilusiones. Turismo y desarrollo en Punta de Mita costa sur de Nayarit. Trabajo de titulación (Licenciatura en Antropología Social). México: Escuela Nacional de Antropología e Historia, 2005.

AZUELA, Antonio, HERRERA, Carlos y SAAVEDRA-HERRERA, Camilo. La expropiación y las transformaciones del estado. Revista Mexicana de Sociología, 2009, vol. 71, núm. 3, p. 525-555.

BAUMAN, Zygmunt. La globalización. Consecuencias humanas. México: Fondo de Cultura Económica, 2010, $171 \mathrm{p}$.

BENAVIDES CORTÉS, Mayela María. Un enclave turístico y el costo social de su proceso de expansión territorial. Revista de Estudios Urbanos y Ciencias Sociales, 2015, vol. 5, núm. 2, p. 95-110.

BENSENY, Graciela. El turismo en México. Apreciaciones sobre el turismo en espacio litoral. Aportes y transferencias, 2007, Vol. 11, núm. 2, p. 13-34.

CÉSAR ARNAIZ, Fernanda. Ciudades Turísticas Desarrollo e Imaginarios Careyes y Nuevo Vallarta. México: Universidad de Guadalajara, 2007, 150 p.

CORDERO Ulate, Aledo. El turismo y la dependencia Latinoamericana. Anuario Social y Politico de América Latina y el Caribe, 2003, Vol. FLACSO/UNESCO/Nueva sociedad, núm. 6, p. 104-111.

CRONISTA OFICIAL DE BAHÍA DE BANDERAS. Datos históricos del área de Nuevo Vallarta. México: Ciudad del Deporte de Bahía de Banderas, 2016.

DÁVILA LÓPEZ, Arturo. Centros integralmente planeados (CIPS) en México: las piezas del proyecto turístico de FONATUR. VI Seminario Internacional de Investigación en Urbanismo. Barcelona: DUOT, 2014.

DIARIO OFICIAL DE LA FEDERACIÓN. Decreto [en línea]: Secretaría de Patrimonio Nacional. 18 de noviembre de 1970. [Fecha de consulta: 5 de marzo de 2017]. Disponible en: http://www.dof.gob.mx/nota_to_imagen_fs.php?cod_diario $=203682$ \&pagina $=4 \&$ seccion $=0$

EL INFORMADOR. Plan experimental en Bahía de Banderas [en línea]. El Informador. 4 de julio de 1971a. [Fecha de consulta: 16 de abril de 2017]. Disponible en: http://hemeroteca.informador.com.mx 
EL INFORMADOR. En Marcha el Complejo Turístico de Costa Alegre [en línea]. El Informador. 12 de octubre de 1971b. [Fecha de consulta: 16 de abril de 2017]. Disponible en: http://hemeroteca.informador.com.mx

EL INFORMADOR. Desaparece el FONAJE; perdió \$1,500 Millones [en línea]. El Informador. 17 de diciembre de 1977. [Fecha de consulta: 16 de abril de 2017]. Disponible en: http://hemeroteca.informador.com.mx

EL INFORMADOR. Confianza en el Fideicomiso Banderas [en línea]. El Informador. 14 de mayo de 1978. [Fecha de consulta: 16 de abril de 2017]. Disponible en: http://hemeroteca.informador.com.mx

EL INFORMADOR. Gira de JLP por Jalisco y Nayarit Inauguró obras públicas de beneficio público por \$1,200 Millones [en línea]. El Informador. 7 de diciembre de 1980. [Fecha de consulta: 16 de abril de 2017]. Disponible en: http://hemeroteca.informador.com.mx

FONATUR. Proyecto Mar de Cortés [en línea]. Fondo Nacional de Fomento al Turismo. S. F. [Fecha de consulta: 8 de abril de 2017]. Disponible en: http://www.fonatur.gob.mx/gobmx/transparencia/LibrosBlancos/3\%20Proyecto $\% 20 \mathrm{Mar} \% 20$ de\%20Cortes.pdf

FONATUR. Proyectos y desarrollos [en línea]. Fondo Nacional de Fomento al Turismo. 2016. [Fecha de consulta: 13 de abril de 2016]. Disponible en: http://www. fonatur.gob.mx

FORBES MÉXICO. Cirque du Soleil abrirá parque temático en México en 2018 [en línea]. Forbes. 13 de noviembre de 2014. [Fecha de consulta: 16 de abril de 2017]. Disponible en: http://www.forbes.com.mx/cirque-du-soleil-abrira-parque-tematico-en-mexico-en-2018/

GOBIERNO DEL ESTADO DE NAYARIT. Fideicomiso Bahía de Banderas [en línea]. Gobierno del Estado de Nayarit. 2014. [Fecha de consulta: 14 de abril de 2017]. Disponible en:

http://www.nayarit.gob.mx/transparenciafiscal/cuentapublica/tomo6/empresariales/fideicomiso_bahia_banderas.pdf

GÓMEZ JARA, Francisco. Acapulco: despojo y turismo. Problemas del Desarrollo, 1974, vol. 5, núm. 19, p. 126-146.

GUTELMAN, Michel. Capitalismo y reforma agraria en México. México: Era, 1974, 290 p.

HAESBAERT, Rogerio. El mito de la desterritorialización: Del fin de los territorios a la multiterritorialidad. México: Siglo XXI, 2011,328 p.

JIMÉNEZ, Alfonso. Turismo, estructura y desarrollo. México: Editorial Mac Graw Hill, 1992, 487 p.

LANFANT, Marie-Francoise. Introducción: El turismo en el proceso de internacionalización. Revista Internacional de ciencias sociales, 1980, vol. 32, núm. 1, p. 14-45.

LEFEBVRE, Henri. Espacio y Politica. El derecho a la ciudad II. Barcelona: Ediciones Península, 1976, 145 p. 
MÁRQUEZ GONZÁLEZ, Antonio Romualdo y SÁNCHEZ CRISPÍN, Álvaro. Turismo y ambiente: la percepción de los turistas nacionales en Bahía de Banderas, Nayarit, México. Investigaciones geográficas, 2007, núm. 64, p. 134-152.

MARTÍNEZ HERNÁNDEZ, Virginia. La urbanización del suelo ejidal, o de cómo la $<<$ irregularidad $>>$ se convirtió en la $<<$ regularidad $>>$ para acceder a la tierra. En NÚÑEZ MARTÍNEZ, Patricia y RODRÍGUEZ CARRANZA, Roberto. Sociedad y Economía, estudios sobre Puerto Vallarta y su región. México: Universidad de Guadalajara, 2009, p. 189-212.

MASSÉ MAGAÑA, Mariel Verónica. Megaproyectos turísticos y comunidades locales: desterritorialización y efectos ambientales en Nuevo Vallarta, México. Trabajo de titulación (Maestría en Ciencias Ambientales) Toluca, Universidad Autónoma del Estado de México, 2017, 150 p.

MILIBAND, Ralph. The State in Capitalist Society. London: Weidenfeld and Nicolson, $1969,294 \mathrm{p}$.

MONTERROSO SALVATIERRA, Neptalí y ZIZUMBO VILLARREAL, Lilia. La reconfiguración neoliberal de los ámbitos rurales a partir del turismo ¿Avance o retroceso? Convergencia Revista de Ciencias Sociales, 2009, vol. 16, núm. 50, p. 133-164.

NAVARRO TRUJILLO, Mina Lorena. Luchas por lo común Antagonismo social contra el despojo capitalista de los bienes naturales en México. México: Bajo Tierra Ediciones y Benemérita Universidad Autónoma de Puebla (BUAP), 2015, 304 p.

OLIVERA LOZANO, Guillermo. La reforma al artículo 27 constitucional y la incorporación de las tierras ejidales al mercado legal de suelo urbano en México. Revista electrónica de geografía y ciencias sociales, 2005, vol. 9, núm. 194 (33).

ONU. Recommendations on international travel and tourism, United Nations, Conférence de Rome. Roma: Organización de las Naciones Unidas, 1963.

OSORIO, Jaime. Estado, biopoder y exclusión. Madrid: Editorial Anthropos y Universidad Autónoma Metropolitana, 2012, 159 p.

OSORIO, Jaime. El estado en el centro de la mundialización: la sociedad civil y el asunto del poder. México: Fondo de Cultura Económica, 2014, 291 p.

PALAFOX MUÑOZ, Alejandro, ZIZUMBO VILLAREAL, Lilia, ARRIAGA ÁLVAREZ, Emilio y MONTERROSO SALVATIERRA, Neptalí. Introducción al estudio del turismo a través del materialismo cultural. Polis, 2010, vol. 9, núm. 25, p. 461-486.

PALAFOX MUÑOZ, Alejandro, ZIZUMBO VILLAREAL, Lilia y ARRIAGA ÁLVAREZ, Emilio. El turismo como eje de acumulación: caso del sector hotelero en México. Multiciencias, 2010, vol. 2, núm. 10, p. 193-201.

PALAFOX MUÑOZ, Alejandro. El turismo como eje de acumulación y factor de transformación del paisaje en Cozumel, México. Trabajo de titulación (Doctorado en Ciencias Ambientales). Toluca, Estado de México: México, 2011.

PALAFOX MUÑOZ, Alejandro. El turismo como eje de acumulación. Nómadas (especial), 2013.

RAMÍREZ SÁIZ, Juan Manuel. Turismo y medio ambiente: El caso de Acapulco. Estudios demográficos y urbanos, 1986, vol. 2, núm. 3(6), p. 479-512. 
REAL CARRANZA, Maribel, OLIVARRÍA ZEPEDA, Mariela Yanisei y MADERA PACHECO, Jesús. Expropiación y despojo ejidal, el proceso de transformación ¿Desarrollo turístico en Nayarit? En: VIII Congreso Latinoamericano de Sociología Rural, 15 al 19 de noviembre. Brasil, Pernambuco: Porto de Galinhas, 2010.

ROUX, Rhina. El principe mexicano: subalternidad, historia y Estado. México: Ediciones Era, 2005, 264 p.

SECTUR. Proyecto Mar de Cortés-Barrancas del Sur [en línea]. Secretaría de Turismo. 21 de octubre de 2014. [Fecha de consulta: 5 de abril de 2017]. Disponible en: http://www.sectur.gob.mx/programas/programas-regionales/mar-de-cortes-barrancas-del-cobre/

SECTUR. Sayulita, Nayarit [en línea]. Secretaría de Turismo. 9 de febrero de 2016. [Fecha de consulta: 14 de abril de 2017]. Disponible en: http://www.sectur.gob. $\mathrm{mx} /$ gobmx/pueblos-magicos/sayulita-nayarit/

SUÁREZ, Luis. Los Fideicomisos Ejidales. Revista de México Agrario, 1973, vol. 6 núm. 91, p. 147-164.

VILCHIS ONOFRE, Adrián Alejandro, ZIZUMBO VILLARREAL, Lilia, MONTERROSO SALVATIERRA, Neptalí, ARRIAGA ÁLVAREZ, Emilio Gerardo y PALAFOX MUÑOZ, Alejandro. Dinámicas capitalistas para la acumulación por despojo. Revista Ciencias Sociales, 2016, vol. 1, núm. 151, p. 31-41.

(c) Copyright: Mariel Massé Magaña, Lilia Zizumbo Villarreal, Alejandro Palafox Muñoz, 2018.

(c) Copyright: Scripta Nova, 2018.

Ficha bibliográfica:

MASSÉ MAGAÑA, Mariel, ZIZUMBO VILLARREAL, Lilia, PALAFOX-MUÑOZ, Alejandro. El megaproyecto Nuevo Vallarta (México). Desterritorialización y afectaciones ambientales. Scripta Nova. Revista Electrónica de Geografía y Ciencias Sociales. Barcelona: Universitat de Barcelona, 15 de enero de 2018, vol. XXII, no 582. [ISSN: 1138-9788] 